\title{
Mechanisms of the antitumor action of the new antibiotic NC0604, a member of the bleomycin family
}

\author{
WEIWEI SHI*, CAIXIA CHEN*, XIUMIN ZHANG, HONGZHANG XU, RUXIAN CHEN and QIYANG HE \\ Institute of Medicinal Biotechnology, Peking Union Medical College and \\ Chinese Academy of Medical Sciences, Beijing 100050, P.R. China
}

Received February 25, 2010; Accepted April 29, 2010

DOI: $10.3892 /$ or_00000901

\begin{abstract}
NC0604, the new antibiotic of the bleomycin family, was isolated from the fermentation broth of Streptomyces verticillus var. pingyangensis n.sp. In this study, we investigated its mechanisms of antitumor action in vitro and in vivo. The results showed that the colony formation inhibition of NC0604 was 2-10 times higher than that of bleomycin to several tumor cell types. In comparison to bleomycin, a better antitumor efficacy of NC0604 was observed in the BALB/c mice loading mouse hepatoma $\mathrm{H} 22$ tumors. Flow cytometry assay detected an increase of intracellular reactive oxygen species and arrest at $\mathrm{G}_{2} / \mathrm{M}$ phase in human hepatoma HepG2 cells after exposure to NC0604. The comet of DNA damage was also observed in the NC0604-treated cells using single cell gel electrophoresis assay. The chromatin condensation appeared in the NC0604induced apoptotic cells. The activation of apoptotic caspase pathway and increase of apoptosis-modulated protein expression, such as p53, Bax, were also detected by Western blot analysis. Taken together, the anti-tumor actions of NC0604 involve activation of the apoptotic pathway and it is valuable for further drug development.
\end{abstract}

\section{Introduction}

Bleomycin (BLM), a potent antitumor antibiotic, has long been used in first line of clinical cancer chemotherapy. It is widely used for several malignant tumor types including squamous cell carcinoma, malignant lymphoma, testicular cancer, ovarian cancer, and in combination with other antitumor agents (1). The mechanism of its action is mediated by the generation of reactive oxygen species

Correspondence to: Dr Qiyang He or Professor Ruxian Chen, Institute of Medicinal Biotechnology, No. 1 Tiantan Xili, Beijing 100050, P.R. China

E-mail: qyh2000bj@yahoo.com.cn

E-mail:chrx888@sohu.com

${ }^{*}$ Contributed equally

Key words: antibiotic NC0604, bleomycin family, apoptosis, antitumor actions, hepatoma
(ROS), and then degraded DNA and RNA in a selective manner $(2,3)$. The advantage of BLM is that it does not cause suppression of bone marrow and immune system. However, its induction of pulmonary fibrosis retards further application in clinic. Therefore, exploring new antibiotics belonging to the BLM family with more effective and lower pulmonary toxicity becomes important.

The new antibiotic NC0604, a member of the BLM family, was first reported by us (4), it was found in the culture broth of Streptomyces verticillus var. pingyangensis n.sp. The clinically used form of BLM contains mixture of BLM A and B. By contrast, $\mathrm{NC} 0604$ has a single chemical structure with a different terminal amine moiety (Fig. 1). It exhibits a broadspectrum antibacterial activities and stronger antitumor activities towards many human tumor cell lines. Moreover, lower pulmonary toxicity was also observed compared with BLM (4). However, it remains unknown how NC0604 inhibits tumor cells.

Accumulating evidence shows that induction of apoptosis plays a very important role in tumor chemotherapy. Both extrinsic and intrinsic apoptotic signaling pathways are triggered by many antitumor agents $(5,6)$. Previous studies showed induction of apoptosis by BLM is accomplished by mitochondria-mediated apoptotic pathway (intrinsic), without involving Fas receptor-mediated apoptotic pathway $(7,8)$. Increase of P53 expression after treatment with BLM was detected in malignant and normal cells $(9,10)$.

In the present study, we investigated the mechanisms of antitumor action of $\mathrm{NC0604}$ in vitro and in vivo. The results show that it has more potent efficacy than that of BLM. Activation of apoptotic caspase pathway contributes to its action towards tumor cells. NC0604 is valuable for further drug development.

\section{Materials and methods}

Reagents. NC0604 was extracted from the fermentation broth of Streptomyces verticillus var. pingyangensis n.sp and purified according to the method reported previously (4). The purity was $>90 \%$ by the HPLC examination. It was prepared into a $2 \mu \mathrm{M}$ solution with PBS buffer and stored at $-20^{\circ} \mathrm{C}$ before use. BLM was purchased from Nippon Kayaku (Tokyo, Japan) and dissolved in PBS at $10 \mathrm{mg} / \mathrm{ml}$. DMSO, 3-(4, 5-dimethyl-2 thiazoyl)-2, 5-diphenyl-2H-tetrazolium bromide (MTT), Hoechst 33342, propidium iodide (PI) were purchased 
from Sigma-Aldrich Chemical Inc. (St. Louis, MO, USA). H2DFFDA, RPMI-1640 medium was obtained from Invitrogen (Carlsbad, CA, USA).

Cell lines and culture condition. Human hepatoma HepG2 cells, human breast cancer MCF-7 cells and human aryngocarcinoma KB cells were cultured in RPMI-1640 medium supplemented with $10 \%$ fetal bovine serum (Tianjin Haoyang Biotech Company, Tianjin, China), 2 mM glutamine, $100 \mathrm{U} / \mathrm{ml}$ penicillin and streptomycin, respectively. The cells were incubated at $37^{\circ} \mathrm{C}$ in humidified $5 \% \mathrm{CO}_{2}$.

Animals. Female BALB/c mice, 6 to 8 -week old, weighing 20-22 g, were purchased from the Institute for Experimental Animals, Chinese Academy of Medical Sciences, Beijing. Animal care was in compliance with the regulation issued by the Beijing Committee of Laboratory Animals. Animals were maintained under specific pathogen-free conditions and provided with sterile food and water ad libitum. Before beginning the experiment, mice were allowed to acclimate for 3 days.

Colony formation assay. Cells were seeded in a 48-well plate at the density of 100 cells per well for $24 \mathrm{~h}$ and then treated with the drugs for 7 days. The cells were fixed in $1 \mathrm{ml}$ methanol for $10 \mathrm{~min}$ and stained with $0.02 \%$ amido black for $10 \mathrm{~min}$. The number of colonies with total cell number over 50 cells was scored. The colony formation efficiency was calculated as percentage of the control values. All experiments were performed in triplicate and were repeated twice.

In vivo therapeutic efficacy. Each mouse was injected with $2 \times 10^{6}$ mouse hepatoma $\mathrm{H} 22$ cells into right lacteral chest wall of the axilla. After 5 days of inoculation, tumor-bearing animals were randomly allocated into 7 groups $(n=9$ per group). Mice were intraperitoneally administered 5 times every 3 days with BLM or NC0604 at 10,5,2 mg/kg, while control group were administered with saline. In addition, mice were weighed and tumor size was measured every 3 days. The tumor volume was calculated by the formula: $W^{2} L \times 1 / 2$, where $W$ and $L$ are the width and length of the tumor, respectively. On day 19 after tumor cell inoculation, mice were sacrificed, and tumors were removed and weighed. The ratio of tumor growth inhibition was calculated by the formula: (A-B)/A x100\% (A: Average tumor weight of control group; B: Average tumor weight of experimental group).

Cell cycle analysis. The HepG2 cells were treated with the drugs for $24 \mathrm{~h}$. The assay was carried out according to the previous methods reported by us (11).

Observation of chromatin condensation. Cells $\left(2 \times 10^{5}\right.$ per well) were seeded in a 6-well plate for $24 \mathrm{~h}$ and treated with NC0604 for $48 \mathrm{~h}$. The suspended and adherent cells were collected and incubated with $2 \mu \mathrm{g} / \mathrm{ml}$ Hoechst 33342 at $37^{\circ} \mathrm{C}$ for $30 \mathrm{~min}$. Chromatin condensation was observed with a fluorescence microscopy (Nikon, Japan).

Measurement of ROS. Cells were seeded in a 6-well plate for $24 \mathrm{~h}$. After the treatment with NC0604 for $12 \mathrm{~h}$, the cells

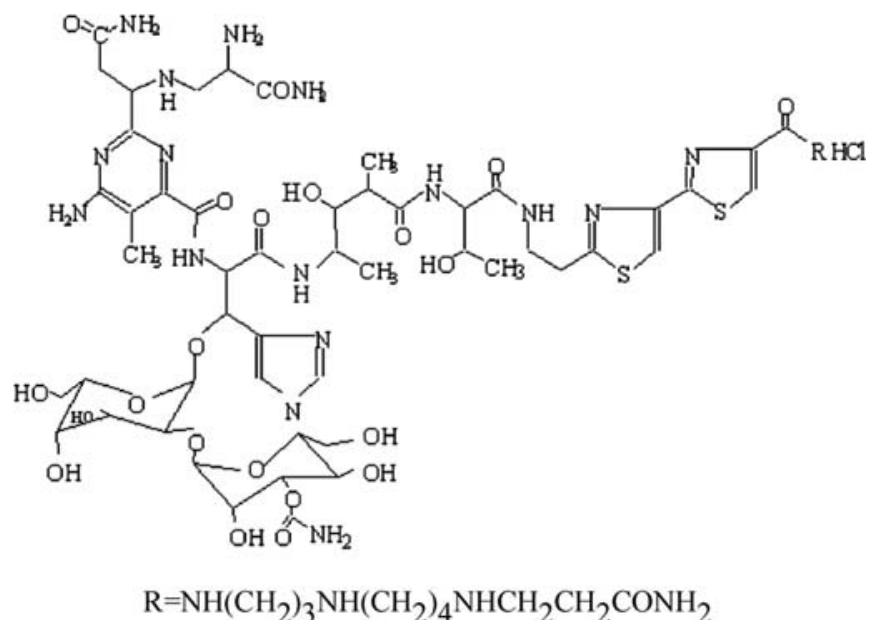

Figure 1. The chemical structure of NC0604.

were washed once with PBS and incubated with $10 \mu \mathrm{mol} / \mathrm{l}$ H2DFFDA for $30 \mathrm{~min}$ at $37^{\circ} \mathrm{C}$. Thereafter, cells were washed with PBS and harvested by trypsinization. The fluorescent intensity was determined with the FACScalibur flow cytometer.

Single cell gel electrophoresis assay. After the treatment with $\mathrm{NC} 0604$ for $6 \mathrm{~h}$, the cells were harvested by trypsinization and collected at $1000 \mathrm{rpm}$ for $5 \mathrm{~min}$. Cells were suspended in $1 \mathrm{ml}$ of $0.5 \%$ low melting agarose dissolved in PBS, and spread on the normal agarose-coated $(1 \%)$ slides. The slides were put at $4^{\circ} \mathrm{C}$ to solidify the low melting agarose. After treatment with lysing solution $\left(2.5 \mathrm{M} \mathrm{NaCl}, 100 \mathrm{mM} \mathrm{Na}_{2}-\right.$ EDTA, $10 \mathrm{mM}$ Tris base, $0.02 \mathrm{M} \mathrm{NaOH}, 1 \%$ Triton-X 100 and $10 \% \mathrm{DMSO}$ ) at $4^{\circ} \mathrm{C}$ for $1 \mathrm{~h}$, the slides were transferred to an alkaline buffer $\left(1 \mathrm{mmol} / 1 \mathrm{Na}_{2}\right.$-EDTA, $300 \mathrm{mmol} / \mathrm{l} \mathrm{NaOH}$, $\mathrm{pH}>13$ ) for $20 \mathrm{~min}$ to unwind the DNA, and run electrophoresis in the same buffer for $20 \mathrm{~min}$ at $20 \mathrm{~V}$ at $4^{\circ} \mathrm{C}$. The solution was neutralized with $0.4 \mathrm{~mol} / \mathrm{l}$ Tris buffer $(\mathrm{pH} 7.5)$. Thereafter, all slides were stained with $2 \mathrm{mg} / \mathrm{ml}$ PI and examined under a fluorescence microscope.

Western blot analysis. After the treatment with NC0604 for $48 \mathrm{~h}$, the HepG2 cells were harvested. The analysis was carried out following the previously reported method (11). Antibodies against bcl-2, Bcl-xL, Bax, Survivin, cleavedcaspase-9, procaspase-3 and PARP were purchased from Cell Signaling Technology (Beverly, MA, USA). Anti-P53 and anti-actin antibodies were from Santa Cruz Biotechnology (Santa Cruz, CA, USA).

Statistics analysis. Results are indicated as the means \pm SD. Comparison between two groups was analyzed by using the Student's t-test, with $\mathrm{P}<0.05$ considered to be statistically significant.

\section{Results}

Inhibition of colony formation by NC0604 in tumor cells. In our previous study, potent growth-inhibitory effects of NC0604 was observed with MTT assay (4). To further compare the 
Table I. The $\mathrm{IC}_{50}$ value of colony formation inhibited by NC0604 and BLM on tumor cells.

\begin{tabular}{lcc}
\hline Cell lines & $\mathrm{NC} 0604\left(\mathrm{IC}_{50}, \mathrm{nM}\right)$ & $\mathrm{BLM}\left(\mathrm{IC}_{50}, \mathrm{nM}\right)$ \\
\hline HepG2 & $0.64 \pm 0.04$ & $6.70 \pm 0.10$ \\
KB & $0.76 \pm 0.08$ & $3.70 \pm 0.05$ \\
MCF-7 & $0.50 \pm 0.02$ & $2.16 \pm 0.07$ \\
MCF-7/DOX & $0.27 \pm 0.07$ & $6.28 \pm 0.09$ \\
\hline
\end{tabular}

The cells were seeded in a 48-well plate ( 100 cells per well) for $24 \mathrm{~h}$ and then treated with the drugs for 7 days. The number of colonies ( $>50$ cells) was scored. The colony forming efficiency was calculated as percentage of the control values. All experiments were performed in triplicate and were repeated twice.

inhibitory action of NC0604 and BLM in tumor cells, colony formation assay was used. The $\mathrm{IC}_{50}$ values of $\mathrm{NC0604}$ for HepG2 and $\mathrm{KB}$ were $0.64 \mathrm{nM}$ and $0.76 \mathrm{nM}$, respectively (Table I). It is noteworthy that the multidrug resistant MCF7/DOX cells were more sensitive to NC0604 than the MCF-7 cells. Consistent with the results obtained by MTT assay, the growth-inhibitory effect of NC0604 was stronger than that of BLM towards these tumor cell lines (Table I). As hepatoma HepG2 cells are more sensitive to NC0604, it prompted us to further study the mechanism of $\mathrm{NC0604}$ on hepatoma.

Potent inhibition of mouse hepatoma by NC0604 in vivo. We next assessed the inhibitory effect of NC0604 on tumor growth in the BALB/c loading mouse hepatoma $\mathrm{H} 22$ tumors. Results revealed that the tumor volumes were significantly suppressed after administration of NC0604 and BLM, compared with the control group (Fig. 2A and B). After mice were sacrificed, tumors were taken and weighed. In NC0604treated groups, the inhibition ratios of tumor growth reached $91.5,79.7$ and $70.0 \%$ at the doses of 10,5 and $2 \mathrm{mg} / \mathrm{kg}$, higher than that of BLM, respectively (Fig. 2C). The data suggest that $\mathrm{NC0604}$ treatment gave superior antitumor effects over that of BLM. In addition, there was no significant body weight loss in the NC0604 and bleomycin-treated groups compared with the control group (data not shown).

Arrest of HepG2 cells at $G_{2} / M$ phase by NC0604. It has been reported that BLM retarded the cells at $\mathrm{G}_{2} / \mathrm{M}$ phase. It can be

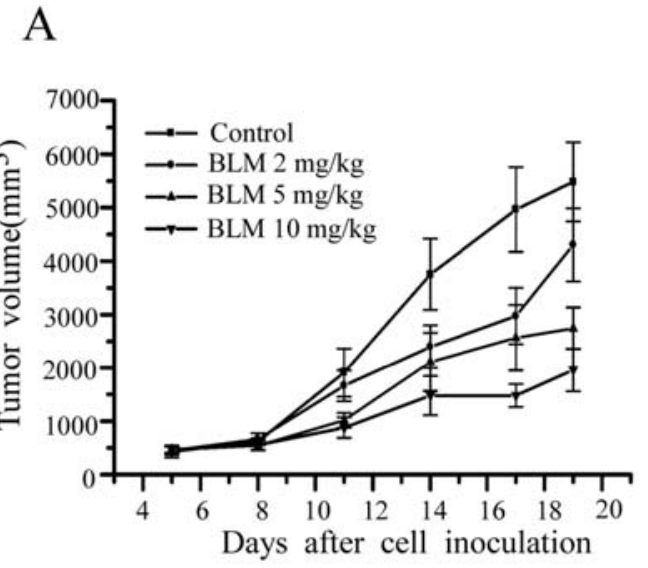

B
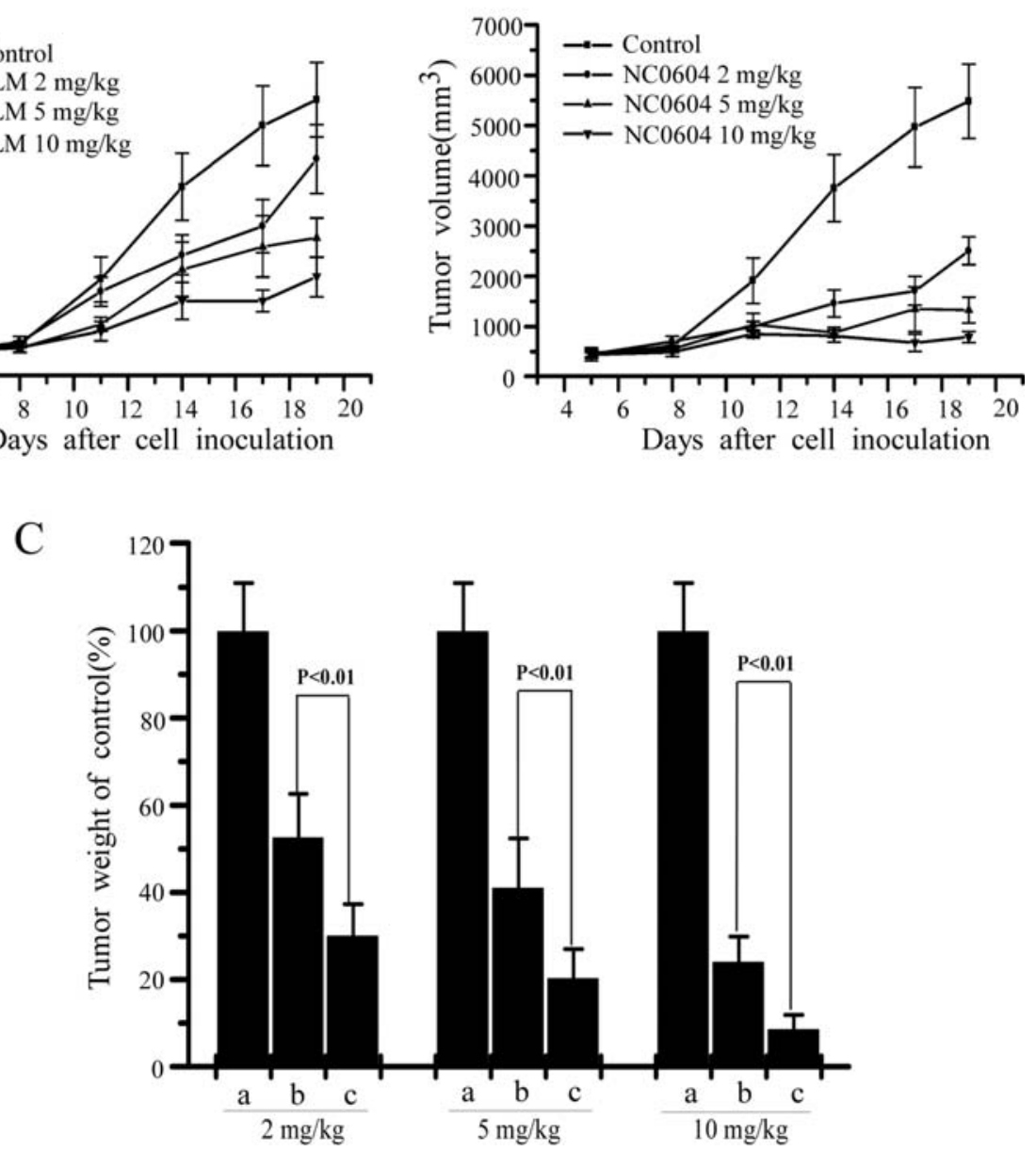

Figure 2. Inhibition of mouse hepatoma H22 tumor growth by NC0604 and BLM. After 5 days of inoculating hepatoma H22 cells, tumor-bearing BALB/c mice were intraperitoneally administrated 5 times every 3 days with BLM or NC0604 at 10, 5, $2 \mathrm{mg} / \mathrm{kg}$, while control group was administered with saline. The mice were weighed and tumor size was measured every 3 days. On day 19 after tumor cell inoculation, mice were sacrificed, and tumors were removed and weighed. (A) Change of tumor volume after administration with BLM (n=9); (B) change of tumor volume after administration with NC0604 (n=9); (C) the percentages of tumor weight (control 100\%) are shown as per the last day of the animal experiment. a: control group, b: BLM group, c: NC0604 group. 

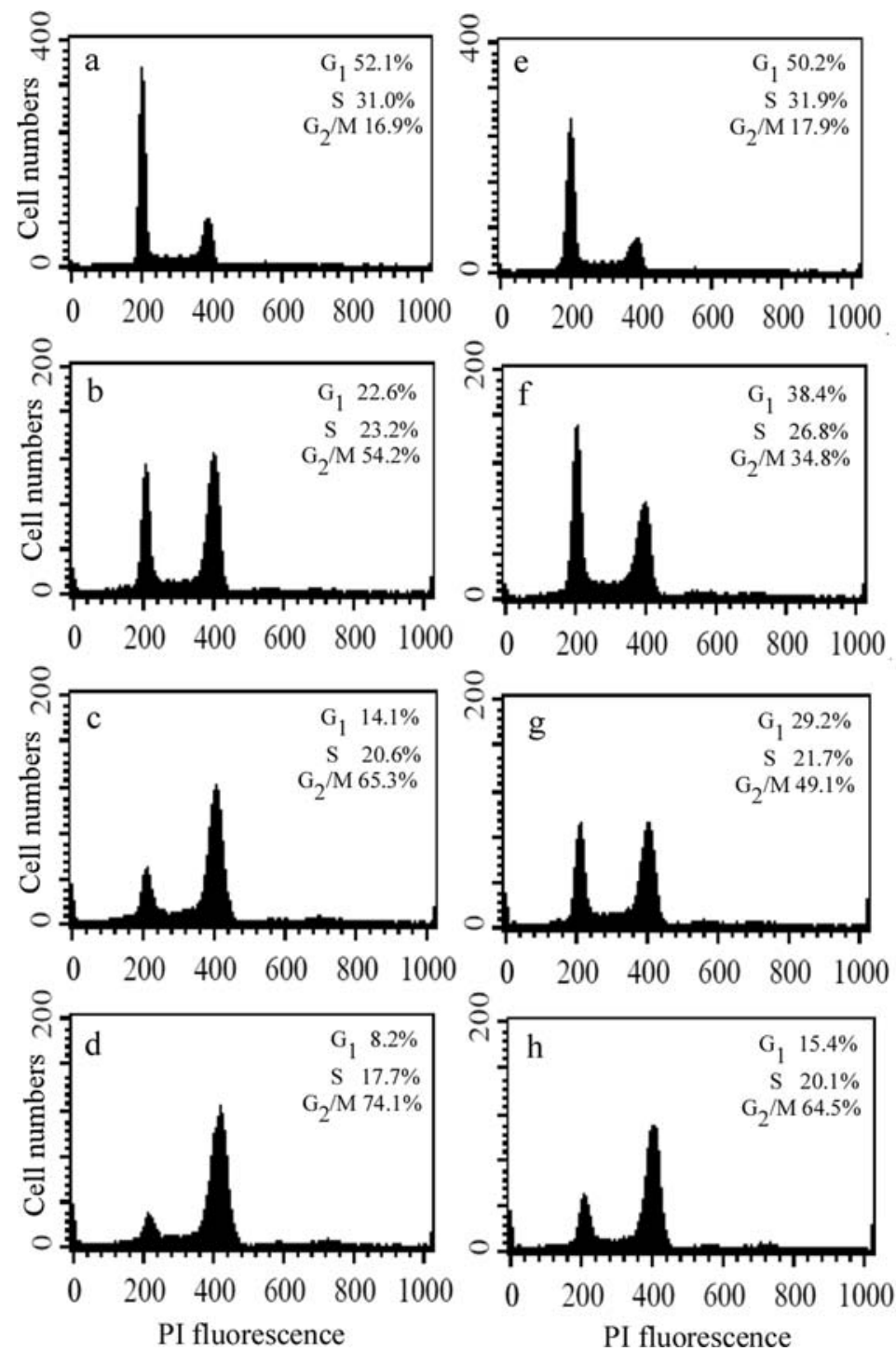

Figure 3. Arrest of HepG2 cells at $\mathrm{G}_{2} / \mathrm{M}$ phase by NC0604 and BLM. The cells were treated with the drugs for $24 \mathrm{~h}$ : (a) and (e) control; (b) $0.2 \mu \mathrm{M} \mathrm{NC} 0604$; (c) $0.5 \mu \mathrm{M} \mathrm{NC0604;} \mathrm{(d)} 1 \mu \mathrm{M} \mathrm{NC0604;} \mathrm{(f)} 0.2 \mu \mathrm{M}$ BLM; (g) $0.5 \mu \mathrm{M}$ BLM; (h) $1 \mu \mathrm{M}$ BLM. The fixed cells were stained with PI and detected by flow cytometry. The results are representative of two separate experiments.
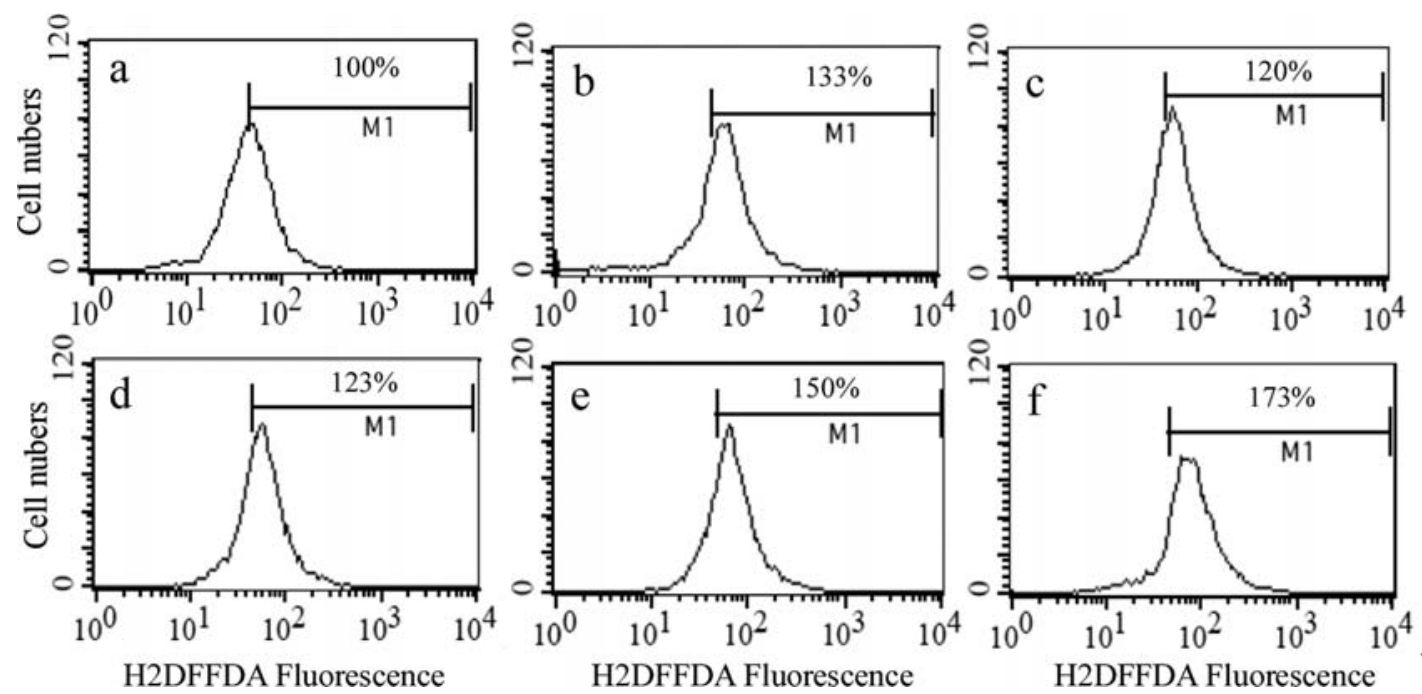

Figure 4. Accumulation of intracellular ROS triggered by NC0604 and BLM. The HepG2 were treated with the drugs for $12 \mathrm{~h}$ : (a) control; (b) $2 \mu \mathrm{M}$ BLM; (c) $0.2 \mu \mathrm{M}$ NC0604; (d) $0.5 \mu \mathrm{M}$ NC0604; (e) $1 \mu \mathrm{M}$ NC0604; (f) $2 \mu \mathrm{M}$ NC0604. The cells were incubated with H2DFFDA for $1 \mathrm{~h}$ and detected by flow cytometry. The results are representative of two separate experiments. 

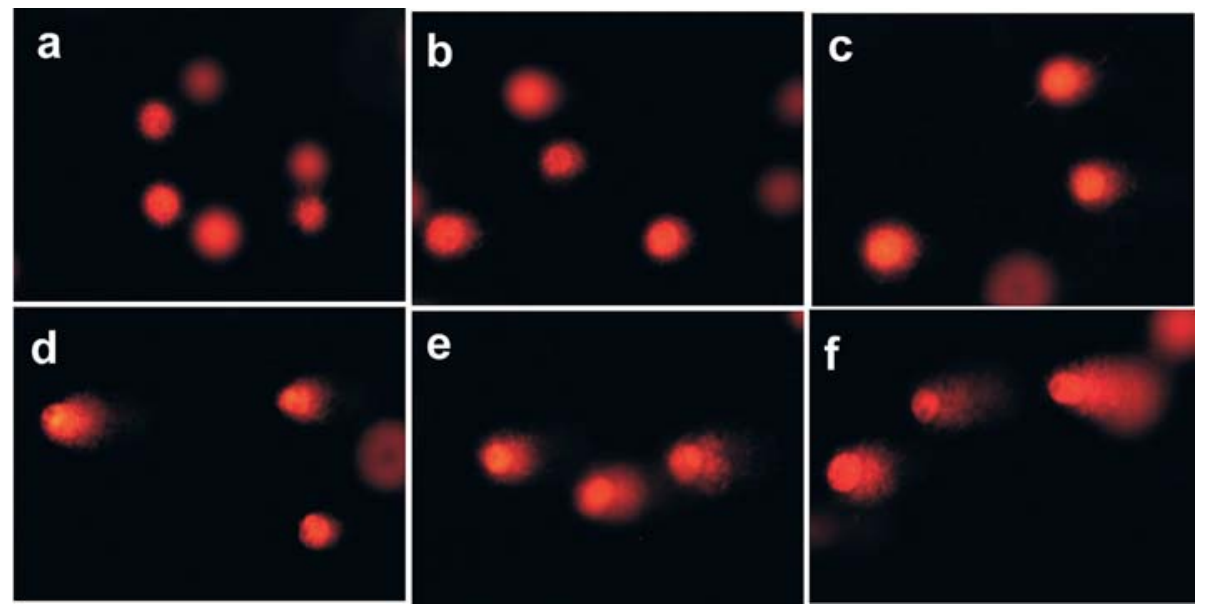

Figure 5. Comets of DNA lesion damaged by NC0604 in the HepG2 cells. The cells were treated with NC0604 for 12 h: (a) control; (b) $0.2 \mu \mathrm{M}$; (c) $0.5 \mu \mathrm{M}$; (d) $1 \mu \mathrm{M}$; (e) $2 \mu \mathrm{M}$; (f) $5 \mu \mathrm{M}$ BLM. The data were obtained with single cell electrophoresis assay. All slides were stained with 2 mg/ml PI and examined under a fluorescence microscope. The results are representative of three separate experiments.
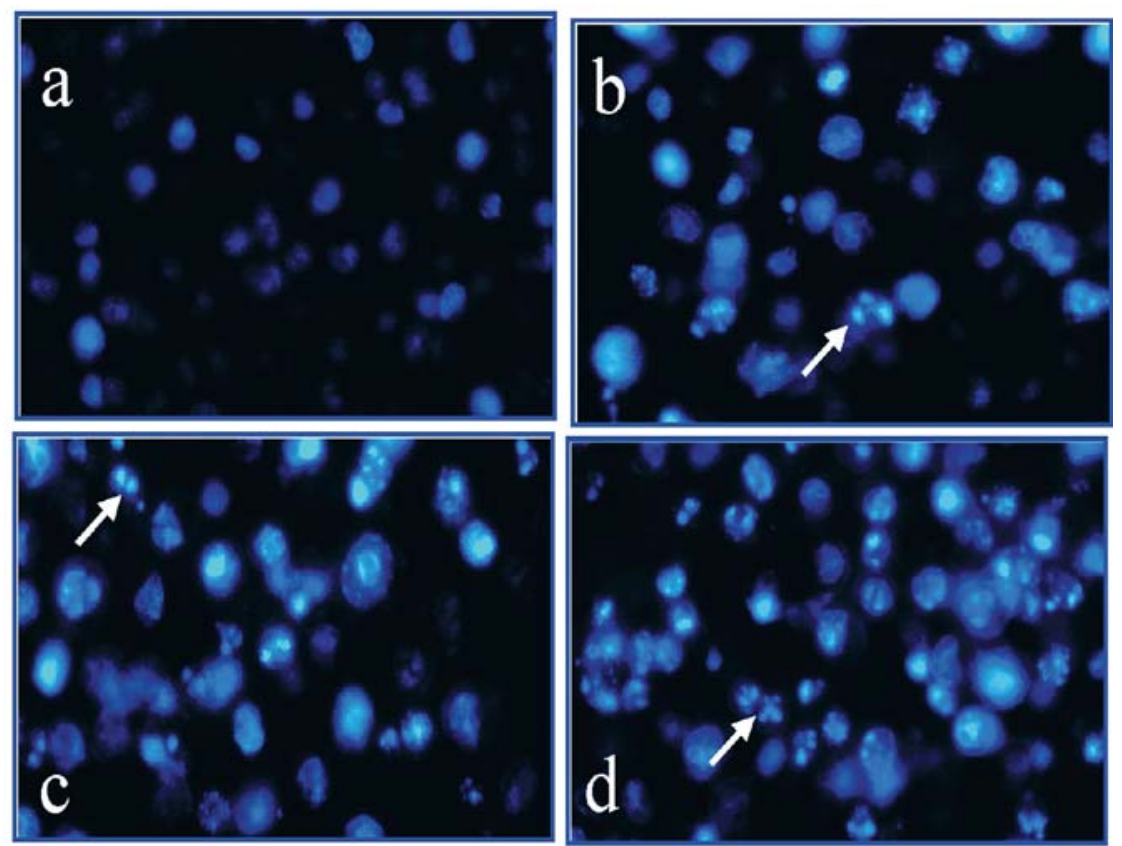

Figure 6. Chromatin condensation of HepG2 cells after exposure to NC0604 for $48 \mathrm{~h}$. (a) Untreated cells, (b) the cells treated with $1 \mu \mathrm{M}$, (c) the cells treated with $2 \mu \mathrm{M}$, (d) the cells treated with $5 \mu \mathrm{M}$. The suspended and adherent cells were collected and stained with $2 \mu \mathrm{g} / \mathrm{ml}$ Hoechst 33342 . The chromatin condensation of the cells was visualized with a fluorescence microscope. Representative results from two independent experiments are shown.

predicted that $\mathrm{NC0604}$ has the same effect on cell cycle distribution. Fig. 3 shows that NC0604 arrested the HepG2 cells at $\mathrm{G}_{2} / \mathrm{M}$ phase in a concentration-dependent manner. Comparing to the same concentration treatments, the percentage of the cells at $\mathrm{G}_{2} / \mathrm{M}$ phase arrested by $\mathrm{NC0604}$ was more than that by BLM, further confirming that the efficacy of $\mathrm{NCO} 004$ is better than that of BLM.

The accumulation of ROS in NC0604-treated HepG2 cells. The intracellular accumulation of ROS is an early critical event in the mitochondrial apoptotic pathway. We next determined the level of intracellular ROS by flow cytometry. The significant ROS accumulation was detected in a concentrationdependent manner after the cells were exposed to increasing concentrations $(0.2,0.5,1,2 \mu \mathrm{M})$ of NC0604 for $12 \mathrm{~h}$ (Fig. 4). When the cells were treated at the same concentration of $2 \mu \mathrm{M}$ for $12 \mathrm{~h}$, the level of intracellular ROS triggered by NC0604 increased 1.7-fold (Fig. 4f), whereas it only increased 1.3fold after exposure to BLM (Fig. 4b).

Induction of DNA damage by NC0604 in the HepG2 cells. To further study the action of NC0604, we performed single cell gel electrophoresis assay to probe whether NC0604 induced DNA lesions in HepG2 cells. The intact cells appeared sphere shaped and the cells with damaged DNA as comets. As shown in Fig. 5, comet DNA tail increased in a concentrationdependent manner after exposure to $\mathrm{NC0604}$ for $6 \mathrm{~h}$, reaching maximum in the $5 \mu \mathrm{M}$ NC0604-treated cells. 


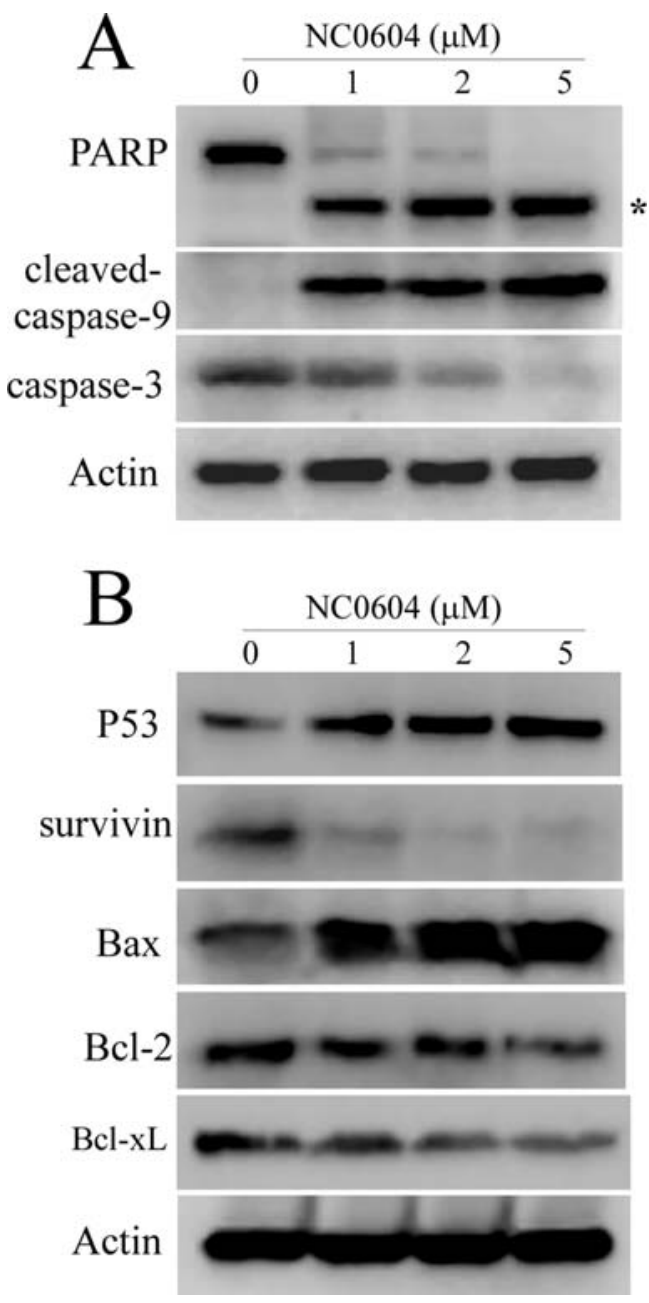

Figure 7. Activation of apoptotic caspase pathway and expressions of apoptosis-regulated proteins after exposure to NC0604. The cells were treated with NC0604 for $48 \mathrm{~h}$. The protein levels were analyzed by Western blotting. (A) Activation of caspase pathway aroused by NC0604. Asterisk (*) indicates cleaved PARP fragments. (B) The expressions of apoptosisregulated proteins. The experiment was repeated twice and similar results were obtained.

Induction of apoptosis by NCO604 in the HepG2 cells. The obvious changes in morphology such as shrinkage and floating cells were observed after the cells were exposed to a higher con-centration of NC0604. To confirm the morphological features of the apoptotic cells we performed Hoechst 33342 staining for DNA. The results showed most of the NC0604treated cells developed typical morphological changes such as chromatin condensation consistent with apoptosis, and the number of these cells increased in a concentration-dependent manner (Fig. 6).

To determine whether NC0604-induced apoptosis is mediated via the activation of caspase pathway, Western blot analysis was performed. The result showed that the activation of caspase-9, -3 and cleavage of PARP were detected in a concentration-dependent manner after exposure to NC0604 for $48 \mathrm{~h}$ (Fig. 7A). To further explore the molecular mechanism of NC0604-induced apoptosis in HepG2 cells, we investigated several key molecules known to regulate apoptosis. The significant increase of P53 and Bax expressions and rapid down-regulation of survivin level were detected, whereas there was a slight decrease in $\mathrm{Bcl}-2$ and $\mathrm{Bcl}-\mathrm{xL}$ protein expression (Fig. 7B).

\section{Discussion}

In this study, we investigated the mechanism of antitumor action of the antibiotic NC0604, using several methods. The data demonstrated potent inhibition in vitro and in vivo, and the efficacy is stronger than that of BLM, used in clinic as antitumor agent. Our previous results showed that NC0604 exerts lower pulmonary toxicity than BLM (4). It can be concluded that NC0604 is a very promising antibiotic as a candidate drug for chemotherapy of human malignancies and deserves further investigation.

It is well known that the action of BLM on tumor cells includes: 1) binding with iron after entrance of the cells, 2) damaging DNA and RNA, 3) determining cell fate response to the damage $(1,12)$. According to the data presented herein, the action of NC0604 is similar to that of BLM. The damage signals triggered by BLM led to generation of ROS and arrest of the cell cycle, finally initiation of the cell death programs, such as apoptosis or senescence $(13,14)$. Our data revealed that intracellular ROS was accumulated, and caspase- 9 and -3 were activated during the progression of NC0604-induced apoptosis, suggesting that it is mediated by the mitochondria apoptotic pathway. Besides activation of caspase apoptotic pathway, NC0604 also led to senescence in the tumor cells (data not shown).

Accumulating evidence shows that many molecules modulate process of apoptosis. The data presented herein showed that the NC0604 treatment resulted in an increase of P53 and Bax protein expressions, rapid down-regulation of survivin protein (Fig. 7B), consistent with previous data reported (15). The tumor suppressor and transcription factor P53 plays a central role in mitochondrial mediated apoptosis (16). It not only drive the expression of downstream target genes, such as Puma, Bax, but also translocates to the cytoplasm forming a complex with Bcl-2 and $\mathrm{Bcl}-\mathrm{xL}$, resulting in cytochrome $\mathrm{c}$ release and caspase activation (17). Moreover, p53 induces the inhibition of survivin at the transcriptional level. Survivin is a member of the inhibitor of apoptosis protein family and is believed to inhibit apoptosis through direct binding to caspase- 3 and -7 , preventing their activation, or inhibiting the AIF pathway $(18,19)$.

Interestingly, NC0604 shows potent inhibition in hepatoma cells. Hepatocellular carcinoma is a critical global health issue $(20,21)$. In China, it ranks second in cancer incidence. It requires further study as to why NC0604 exerts potent cytotoxity in hepatoma cells at molecular level.

In summary, NC0604 induces apoptosis via damage of DNA and increases ROS generation. It is more efficient than that of BLM in vitro and in vivo.

\section{Acknowledgements}

The study was supported by grants from National Scientific Foundation of China (No. 30772284) and Platform for Great Project of Developing New Drugs in China (2009ZX09301003). 


\section{References}

1. Chen J and Stubbe JA: Bleomycins: towards better therapeutics. Nat Rev Cancer 5: 102-112, 2005.

2. Holmes CE, Abraham AT, Hecht SM, Florentz C and Giege R: Fe-bleomycin as a probe of RNA conformation. Nucleic Acids Res 24: 3399-3406, 1996.

3. Steighner RJ and Povirk LF: Bleomycin-induced DNA lesions at mutational hot spots: implications for the mechanism of double-strand cleavage. Proc Natl Acad Sci USA 87: 8350-8354, 1990.

4. Chen C, Si S, He Q, Xu H, Lu M, Xie Y, Wang Y and Chen R: Isolation and characterization of antibiotic NC0604, a new analogue of bleomycin. J Antibiot 61: 747-751, 2008.

5. Johnstone RW, Ruefli AA and Lowe SW: Apoptosis: a link between cancer genetics and chemotherapy. Cell 108: 153-164, 2002.

6. Okada H and Mak TW: Pathways of apoptotic and non-apoptotic death in tumor cells. Nat Rev Cancer 4: 592-603, 2004.

7. Hwang J, Kim YY, Huh S, Shim J, Park C and Kimm K: The time-dependent serial gene response to zeocin treatment involves caspase dependent apoptosis in Hela cells. Microbiol Immunol 49: 331-342, 2005

8. Wallach-Dayan SB, Izbicki G, Cohen PY, Gerstl-Golan R, Fine A and Breuer R: Bleomycin initiates apoptosis of lung epithelial cells by ROS but not by Fas/FasL pathway. Am J Physiol Lung Cell Mol Physiol 290: L790-L796, 2006.

9. Müller M, Strand S, Hug H, Heinemann EM, Walczak H, Hofmann WJ, Stremmel W, Krammer PH and Galle PR: Druginduced apoptosis in hepatoma cells is mediated by the CD95 (APO-1/Fas) receptor/ligand system and involves activation of wild-type p53. J Clin Invest 99: 403-413, 1997.

10. Chang BD, Xuan Y, Broude EV, Zhe H, Schot B, Fang J and Roninson IB: Role of p53 and p $21^{\text {waf } 1 / \text { cip } 1}$ in senescence-like terminal proliferation arrest induced in human tumor cells by chemotherapeutic drugs. Oncogene 18: 4808-4818, 1999.

11. Li Y, Han N, Gao N, Xu R, Sun C, Li D and He Q: Induction of apoptosis by the angucyclinone antibiotic chemomicin in human tumor cells. Oncol Rep 23: 477-483, 2010.
12. Sugiura Y, Suzuki T, Kuwahara J and Tanaka H: On the mechanism of hydrogen peroxide-, superoxide-, and ultraviolet light-induced DNA cleavages of inactive bleomycin-iron (III) complex. Biochem Biophys Res Commun 105: 1151-1158, 1982.

13. Baus F, Gire VR, Fisher D, Piette J and Dulic V: Permanent cell cycle exit in G2 phase after DNA damage in normal human broblasts. EMBO J 22: 3992-4002, 2003.

14. Islaih M, Halstead BW, Kadura IA, Li B, Reid-Hubbard JL, Flick L, Altizer JL, Thom Deahl J, Monteith DK, Newton RK and Watson DE: Relationships between genomic, cell cycle, and mutagenic responses of TK6 cells exposed to DNA damaging chemicals. Mutat Res 578: 100-116, 2005.

15. Christensen JG, Gonzales AJ, Cattley RC and Goldsworthy TL: Regulation of apoptosis in mouse hepatocytes and alteration of apoptosis by nongenotoxic carcinogens. Cell Growth Differ 9: 815-825, 1998.

16. Nayak SK, Panesar PS and Kumar H: p53-Induced apoptosis and inhibitors of p53. Curr Med Chem 16: 2627-2640, 2009.

17. Mihara M, Erster S, Zaika A, Petrenko O, Chittenden T, Pancoska P and Moll UM: p53 has a direct apoptogenic role at the Mitochondria. Mol Cell 11: 577-590, 2003.

18. Tamm I, Wang Y, Sausville E, Scudiero DA, Vigna N, Oltersdorf T and Reed JC: IAP-family protein survivin inhibits caspase activity and apoptosis induced by Fas (CD95), Bax, caspases, and anticancer drugs. Cancer Res 58: 5315-5320, 1998.

19. Shin S, Sung BJ, Cho YS, Kim HJ, Ha NC, Hwang JI, Chung CW, Jung YK and Oh BH: An anti-apoptotic protein human survivin is a direct inhibitor of caspase- 3 and -7 . Biochemistry 40: 1117-1123, 2001.

20. Llovet JM and Bruix J: Hepatitis B virus and hepatocellular carcinoma. J Hepatol 39: 59-63, 2003.

21. Bosch FX, Ribes J and Borras J: Epidemiology of primary liver cancer. Semin Liver Dis 19: 271-285, 1999. 